\title{
Epidemiology and Pathophysiology of Acquired Heart Failures Amenable to Surgical Interventions in the Sub-Saharan Africa
}

\author{
Kelechi E. Okonta ${ }^{1,2}$ \\ ${ }^{1}$ Division of Cardiothoracic Surgery, Department of Surgery, University of Port Harcourt Teaching Hospital, \\ Port Harcourt, Nigeria \\ ${ }^{2}$ Division of Cardiothoracic Surgery, Department of Surgery, Federal Medical Center, Owerri, Nigeria \\ Email: okontakelechi@yahoo.com
}

Received 18 April 2014; revised 18 May 2014; accepted 18 June 2014

Copyright (c) 2014 by author and Scientific Research Publishing Inc.

This work is licensed under the Creative Commons Attribution International License (CC BY). http://creativecommons.org/licenses/by/4.0/

(c) (i) Open Access

\begin{abstract}
Heart failure (HF) is an important cause of morbidity and mortality in sub-Saharan Africa and indeed worldwide. The management of this condition has largely been thought to be within the domain of the Physician with the Surgeon having little or no role to play. The commonest cause of HF that may require surgical intervention is rheumatic valvular heart disease especially in the young age group while ischaemic heart disease still remains at the low rung of the ladder and interestingly, hypertrophic cardiomyopathy is becoming common. Most of the literatures reviewed failed to identify pericardial diseases, though it ranked topmost in the face of tuberculosis and HIV infections in the sub-region, and the other non-cardiac structures as important causes of HF which is amenable to surgical intervention. Equally, what have not been clearly identified are the surgical aspects; indeed its sub-classifications into heart and non-heart causes have hitherto not been documented. Even though these lists from this review are not exhaustive of the numerous unidentified causes of surgical HF, this would act as stimulus for further and extensive documentation of guideline for the recognition of these sub-classifications of HF amenable to surgery.
\end{abstract}

Keywords

Epidemiology and Pathophysiology, Heart Failure, Surgical Intervention, Sub-Saharan Africa

\section{Introduction}

Heart failure (HF) is a clinical syndrome caused by any disorder involving the pericardium, the muscles, valves

How to cite this paper: Okonta, K.E. (2014) Epidemiology and Pathophysiology of Acquired Heart Failures Amenable to Surgical Interventions in the Sub-Saharan Africa. World Journal of Cardiovascular Surgery, 4, 116-122.

http://dx.doi.org/10.4236/wjcs.2014.47018 
or vessels which results in defective heart filling at diastole or impaired heart contraction or emptying with inability to pump adequate amount of blood to support tissue metabolism, or to be able to do so at an elevated filling pressure [1]. Also, some clinical conditions remotely removed from the heart may result in HF by various mechanisms.

The structures that could be affected and thus lead to HF can be succinctly classified into two: the heart and the non heart structures. The heart structures can furthermore be sub-classified into: the pericardium, the myocardium, the coronary arteries, the valves, the conductive tissues. The non-heart structures, outside the heart, that when affected may result in HF requiring surgical interventions, are the thyroid gland in thyroid diseases, peripheral vessels disorder like large arterio-venous fistulae, the pleural space and the lung diseases and off course postoperative low cardiac output.

There is no published literature on acquired HF requiring surgical intervention in SSA [2] and indeed those classifications and sub-classifications have not hitherto been done and thus, this is the first review.

\section{Epidemiology}

In pericardial diseases, tuberculosis accounts for a significant number of pericardial diseases recorded here [3]. Tuberculous infection of the pericardium may give rise to purulent pericardial collection [3] [4] and this in most cases will require surgical intervention alone or in conjunction with medical treatment [5]. A much earlier report in Nigeria showed that tuberculosis was histological diagnosed in $11.1 \%$ in patients with another form of pericardial disease known as constrictive pericarditis [6]. Interestingly, a subset of pericardial disease known as effusive-constrictive pericarditis was stated as deserving a closer attention as treatment was challenging [7]. Also, one of the important causes of pericardial diseases resulting in HF in HIV-AIDS patients, that is amenable to surgery, is pericardial effusion [8]. Thus the duo of tuberculosis and HIV infections which are common in the sub-region, have made the condition of pericardial diseases common [9] [10]. And the outcome of un-drained pericardial effusion associated with HIV infection is cardiac tamponade [11] and that requires urgent surgical intervention to avoid death.

Rheumatic heart disease (RHD) is considered to be relatively common in many parts of Africa, especially amongst young people [12] with valvular disease ranking high amongst the major causes of cardiovascular diseases (CVD) in Africa [13]. From the work done in Nigeria, the commonest causes of HF requiring surgical intervention, besides the three medical conditions listed, was RHD in 4.3\% [14]. Though the prevalence of RHD was noted to be declining considerably as a result of improvements in the primary health care delivery system in the sub-region [15]; a previous study done in Cameroun, observed that the first aetiologic factor of HF in the young was RHD in about 14.6\% [16]. In another study, 572 consecutive patients who were evaluated for HF; it was observed that the main cause of HF, apart from hypertension (21.3\%) was RHD (20.1\%) [17]. In Cape Town, South Africa, it was stated that the causes of HF in Africans remained largely non-ischaemic and that RHD was one of the main contributors to the aetiology of HF in sub-Saharan Africa [18]. A retrospective study in Cameroun of 312 adult patients with CVD, average age 44 years, revealed that RHD occurred in about $25.6 \%$. [19]. In a survey of 1,115 children in Kenya, using echocardiographic method, it showed that the prevalence rate of RHD was 2.7 per 1,000 [20]. A 1993 study of patients admitted to Kenyatta National Hospital with HF revealed that almost 32\% had RHD [21]. RHD remains a major cause of HF in Africa, especially in the young [22].

Cardiomyopathies, especially hypertrophic cardiomyopathy was considered to be more common than Ischaemic Heart Diseases (ISHD) and Hypertrophic cardiomyopathy which was thought to be rare in SSA was becoming common [23]. In earlier prospective review in the northern part of Nigeria, it was observed that cardiomyopathies were the commonest cause of HF in about $47 \%$ of cases reviewed [24]. In a consecutive review of patients coming for HF in a tertiary institution in Ghana showed that cardiomyopathies again, was noted as an important cause of HF [25]. The limitation in the latter two studies was that the cardiomyopathies were summed up without recourse to the ones that are amenable to surgeries like hypertrophic cardiomyopathy.

In the INTERHEART Africa study, ISHD ranked 8th amongst the leading causes of death in men and women in the region [26]. Another review a year afterwards showed that Coronary artery disease (CAD) and its complications were still uncommon in Africa [27]. It was on this strength that the age-standardised mortality rates for ISHD was projected to rise by $27 \%$ in African men and $25 \%$ in women by 2015 , and by $70 \%$ and $74 \%$, respectively by 2030 following a recent systematic review in Botswana [28]. Surprisingly, a 5-year retrospective 
study in North-Eastern, Nigerian stated that the prevalence of ISHD was 3.4\% of all CVD [29]. In Cameroun, a study done between 1992 and 1997 ranked CAD eighth among the CVDs registered with a prevalence of 1.53 percent [30]. Myocardial infarction in black Africans under age 40 years shows characteristics similar to those seen in patients under age 40 in the Western countries [31].

The prevalence of complete heart block in the SSA was high especially amongst the elderly and at sharp apparent contrast to the previous thinking that it was rare and will not merit surgical intervention [32] [33]. However, the aetiology of this condition was not roundly known [33]. Intra-ventricular mal-conductions in African Population seemed to exhibit a prevalence rate that was similar to that in other parts of the world [34].

Thyroid diseases, mainly hyperthyroidism and autoimmune thyroid disorder are associated with CVD leading to HF [35]-[37]. Thyroid disorders are the second most common endocrine disorders in Nigeria and Thyroid disorders in Nigerians are a significant cause of cardiovascular morbidity with complications such as atrial fibrillation and HF [37]. A coexistence of mitral valve prolapsed with autoimmune thyroid disease could explain the cardiovascular importance of thyroid disorder in this setting [36].

Arterio-venous (AV) fistulae is considered common in the sub-region especially with chronic renal failure that will necessitate the creation of AV fistulae using the peripheral vein as the patients wait long on this procedure for dialysis before possibly getting kidney transplant [38] [39].

Pleural and lung Diseases are on the rise in the sub-region, as the incidence of tuberculosis and HIV have made the occurrence of pleural fluid collection and destroyed lungs common [40].

Post cardiac surgery-pericardiectomies for constrictive pericarditis can be problematic [7] as it can lead to low cardiac output, also, after heart surgeries, especially after surgeries for ischaemic heart diseases [41]. The post operative period may be characterized by low cardiac output which may not be amenable to inotrope use, making the surgical intervention by insertion of intra-aortic balloon pump desirable [41].

\section{Pathophysiology}

Pericardial Diseases: Fluid collection in the pericardial space can lead to cardiac tamponade is defined as haemodynamically significant heart compression from excessive or sudden or accumulating pericardial contents that may lead to and possibly defeat compensatory mechanisms [42] [43]. In effusive pericardial disease, the rise in intra-pericardial pressure results in reduced myocardial transmural pressure and filling [43]. The sudden pericardial or excessive fluid accumulation without adequate accommodation by the pericardium leads to increased intra-pericardial pressure resulting in the initial compression of the right atrium and the right ventricle causing a decrease in their diastolic compliances with decreased right ventricular filling decreasing stroke volume and thus cardiac output [43] [44].

Constrictive pericarditis impairs cardiac filling only in late diastole. Thus early diastolic filling of the right ventricle occurs briefly in constrictive pericarditis until the ventricle suddenly reaches the rigid constraint of the pericardium [44]. In constrictive pericarditis, the pericardium looses elasticity as a result of progress fibrosis or dystrophic calcification occasioned by pericardial inflammation [43] and basically, in this condition, the cardiac compression ultimately leads to heart failure from impaired diastolic filling. Effusive-constrictive pericarditis has both components, which is characterized by constriction of visceral pericardium with a coexisting tense pericardial effusion [45]. The hallmark of effusive-constrictive pericarditis is the persistence of elevated right atrial pressure after intrapericardial pressure has been reduced to normal levels by removal of pericardial fluid [46].

The main impact of RHD is on the cardiac valves; with regurgitation of the mitral valve being the commonest disorder in the sub-region [29]. Mitral insufficiency results in retrograde regurgitation of blood from the left ventricle to the left atrium during systole. This regurgitant volume creates a volume overload in the left chambers. The effect of this volume overload on left ventricular performance depends on the severity and the duration of the regurgitation. The two most important compensatory mechanisms are left ventricular dilatation and left ventricular hypertrophy caused by increased wall stress. Left atrial enlargement is another consequence of chronic mitral regurgitation with this enlargement can lead to atrial fibrillation, which in turn decreases ventricular filling [44] [47]. Mitral stenosis is considered when there is reduction in mitral valve area and this leads to an increase in gradient across the atrio-ventricular area. This elevation in left-sided pressures secondarily leads to pulmonary hypertension; when the pulmonary artery systolic pressures increase, there is subsequent gradual rise in both right ventricular end-diastolic pressure and volume [44]. Coronary artery narrowing as a result of atheroma, when significant enough, can lead to myocardial infarctions and myocardial scarring resulting in ab- 
normalities of left ventricular diastolic and systolic dysfunctions [48] [49]. Death can result from acute or sub acute heart failure or sudden ventricular fibrillation [50].

Hypertrophic cardiomyopathy entails an enlargement of the heart muscle, usually that of the left ventricle, but sometimes the right cardiac chamber is also involved. In one form of hypertrophic disease, the septum becomes enlarged and obstructs the flow of blood from the left ventricle into the aorta. The mitral valve also may be rendered incompetent by the thickened septum, resulting to mitral insufficiency [51].

With large AV fistula which is fed by large artery, there will be commensurately increase in venous return in other to maintain the increased cardiac output which is required to sustain the flow of the fistula. The falling peripheral resistance occasioned by the fistula leads to an increase in cardiac output and this can eventually lead to HF [52] [53].

Tension pleural fluid collection will eventually cause the collapse of the pliable vena cavae and impair diastolic filling of the heart [54].

In conduction disorders, atrial fibrillation decreases in ventricular filling by $15 \%$ - $30 \%$ especially in the elderly. In complete heart block, remembering that cardiac output is a direct product of stroke volume and the heart rate and thus the cardiac output decreases in cases of decreased heart rate [55] [56].

In thyroid diseases especially with hyperthyroidism, the impact of the hormones on cardiovascular system are both directly and indirectly [57]-[59] and resulting in increased cardiac contractility, increased cardiac output, and reduced systemic vascular resistance. The cardiac manifestations of thyrotoxicosis are those of HF and atrial fibrillation [35] [37]. Also, in some autoimmune diseases it has been noted to be associated with mitral valve prolapsed [59].

\section{Conclusions}

This is the first review of this kind, albeit, some clinicians may not agree with all of the above enumerated causes of surgical HF. Simply put, surgical HF is any clinical condition that prevents the proper pumping out of blood from the heart chambers or the heart does it at the expense of increased venous return and of which surgery may deservedly effect a cure.

The commonest cause of HF requiring surgical intervention from this review is rheumatic valvular heart disease especially in the young age group while ISHD still remains at the low rung of the ladder, and interestingly, hypertrophic cardiomyopathy is becoming common.

Most of the literatures reviewed failed to identify pericardial diseases and the other non-cardiac structures, when diseased, as the important causes of heart failure which is amenable to surgical intervention.

There has not been any documented account of the sub-classification of HF amenable to surgery in the subSaharan African region and indeed the whole world. However, what is needed is a regional approach to accurately document all the HF that may require surgical intervention.

\section{Conflict of Interests}

No conflicts of interest in this work.

\section{References}

[1] Akinkugbe, O.O. and Falase, A.O. (1987) Clinical Medicine in the Tropics Series: Cardiovascular Disease. Blackwell Scientific Publications, Hoboken, 65.

[2] Mayosi, B.M. (2007) Contemporary Trends in the Epidemiology and Management of Cardiomyopathy and Pericarditis in Sub-Saharan Africa. Heart, 93, 1176-1183. http://dx.doi.org/10.1136/hrt.2007.127746

[3] Tettey, M., Sereboe, L., Aniteye, E., Edwin, F., Kotei, E., Tamatey, M., et al. (2007) Surgical Management of Constrictive Pericarditis. Ghana Medical Journal, 41, 190-193.

[4] Massoure, P.L., Boddaert, G., Caumes, J.L., Gaillard, P.E., Lions, C. andGrassin, F. (2010) Porridge-Like Tuberculous Cardiac Tamponade: Treatment Difficulties in the Horn of Africa. General Thoracic and Cardiovascular Surgery, 58, 276-278. http://dx.doi.org/10.1007/s11748-009-0525-y

[5] Strang, J.I., Nunn, A.J., Johnson, D.A., Casbard, A., Gibson, D.G. and Girling, D.J. (2004) Management of Tuberculous Constrictive Pericarditis and Tuberculous Pericardial Effusion in Transkei: Results at 10 Years Follow-Up. QJM, 97, 525-535. http://dx.doi.org/10.1093/qjmed/hch086 
[6] Mabogunje, O.A., Adesanya, C.O., Khwaja, M.S., Lawrie, J.H. and Edington, G.M. (1981) Surgical Management of Pericarditis in Zaria, Nigeria. Thorax, 36, 590-595. http://dx.doi.org/10.1136/thx.36.8.590

[7] Salami, M.A., Adeoye, P.O., Adegboye, V.O. and Adebo, O.A. (2012) Presentation Pattern and Management of Effusive-Constrictive Pericarditis in Ibadan. Cardiovascular Journal of Africa, 23, 206-211. http://dx.doi.org/10.5830/CVJA-2011-066

[8] Abubakar, U., Adeoye, P.O., Adebo, A.O., Adegboye, V.A., Kesieme, E.B. and Okonta, K.E. (2011) Pattern of Pericardial Diseases in HIV-Positive Patients at University College Hospital, Ibadan, Nigeria. Southern African Journal of HIV Medicine, 12, 25-26.

[9] Nzuobontane, D., Blackett, K.N. and Kuaban, C. (2002) Cardiac Involvement in HIV Infected People in Yaounde, Cameroon. Postgraduate Medical Journal, 78, 678-681. http://dx.doi.org/10.1136/pmj.78.925.678

[10] Magula, N.P. and Mayosi, B.M. (2003) Cardiac Involvement in HIV-Infected People Living in Africa: A Review. Cardiovascular Journal of South Africa, 14, 231-237.

[11] Nkoua, J.L., Tsombou, B. and Bouramoue, C. (1999) Non Rheumatic Pericarditis with Effusion: Causes, Outcome and Relation to HIV-Infection. Annals of Oncology, 25, 3-6.

[12] Ekra, A. and Bertrand, E. (1992) Rheumatic Heart Disease in Africa. World Health Forum, 13, 331-333.

[13] Essop, M.R. and Nkomo, V.T. (2005) Rheumatic and Nonrheumatic Valvular Heart Disease: Epidemiology, Management, and Prevention in Africa. Circulation, 112, 3584-3591. http://dx.doi.org/10.1161/CIRCULATIONAHA.105.539775

[14] Onwuchekwa, A.C. and Asekomeh, G.E. (2009) Pattern of Heart Failure in a Nigerian Teaching Hospital. Vascular Health and Risk Management, 5, 745-750. http://dx.doi.org/10.2147/VHRM.S6804

[15] Akinwusi, P.O., Peter, J.O., Oyedeji, A.T. and Odeyemi, A.O. (2013) The New Face of Rheumatic Heart Disease in South West Nigeria. International Journal of General Medicine, 6, 375-381. http://dx.doi.org/10.2147/IJGM.S44289

[16] Tantchou Tchoumi, J.C., Ambassa, J.C., Kingue, S., Giamberti, A., Cirri, S., Frigiola, A., et al. (2011) Occurrence, Aetiology and Challenges in the Management of Congestive Heart Failure in Sub-Saharan Africa: Experience of the Cardiac Centre in Shisong, Cameroon. The Pan African Medical Journal, 8, 11.

[17] Mendez, G.F. and Cowie, M.R. (2001) The Epidemiological Features of Heart Failure in Developing Countries: A Review of the Literature. International Journal of Cardiology, 80, 213-219. http://dx.doi.org/10.1016/S0167-5273(01)00497-1

[18] Ntusi, N.B. and Mayosi, B.M. (2009) Epidemiology of Heart Failure in Sub-Saharan Africa. Expert Review of Cardiovascular Therapy, 7, 169-180. http://dx.doi.org/10.1586/14779072.7.2.169

[19] Kotto, R.M. and Bouelet, B.A. (2000) Cardiovascular Diseases in Adults in Douala, Cameroon. Cardiologie Tropicale, 26, 61-64.

[20] Anabwani, G.M. and Bonhoeffer, P. (1996) Prevalence of Heart Disease in School Children in Rural Kenya Using Colour-Flow Echocardiography. East African Medical Journal, 73, 215-217.

[21] Oyoo, G.O. and Ogola, E.N. (1999) Clinical and Socio Demographic Aspects of Congestive Heart Failure Patients at Kenyatta National Hospital, Nairobi. East African Medical Journal, 76, 23-27.

[22] Mendez, G.F. and Cowie, M.R. (2001) The Epidemiological Features of Heart Failure in Developing Countries: A Review of the Literature. International Journal of Cardiology, 80, 213-219. http://dx.doi.org/10.1016/S0167-5273(01)00497-1

[23] Falase, A.O. and Ogah, O.S. (2012) Cardiomyopthies and Myocardial Disorders in Africa: Present Status and the Way Forward. Cardiovascular Journal of Africa, 23, 553-562. http://dx.doi.org/10.5830/CVJA-2012-046

[24] Antony, K.K. (1980) Pattern of Cardiac Failures in Northern Savanna Nigeria. Tropical and Geographical Medicine, 32, 118-125.

[25] Amoah, A.G. and Kallen, C. (2000) Aetiology of Heart Failure as Seen from a National Cardiac Referral Centre in Africa. Cardiology, 93, 11-18. http://dx.doi.org/10.1159/000006996

[26] Mensah, G.A. (2008) Ischaemic Heart Disease in Africa. Heart, 94, 836-843. http://dx.doi.org/10.1136/hrt.2007.136523

[27] Ntusi, N.B.A. and Mayosi, B.M. (2009) Epidemiology of Heart Failure in Sub-Saharan Africa. Expert Review of Cardiovascular Therapy, 7, 169-180. http://dx.doi.org/10.1586/14779072.7.2.169

[28] Onen, C.L. (2013) Epidemiology of Ischaemic Heart Disease in Sub-Saharan Africa. Cardiovascular Journal of Africa, 24, 34-42. http://dx.doi.org/10.5830/CVJA-2012-071

[29] Sani, M.U., Adamu, B., Mijinyawa, M.S., Abdu, A., Karaye, K.M., Maiyaki, M.B., et al. (2006) Ischaemic Heart Disease in Aminu Kano Teaching Hospital, Kano, Nigeria: A 5-Year Review. Nigerian Journal of Medicine, 15, 128-131. 
http://dx.doi.org/10.4314/njm.v15i2.37095

[30] Mbanya, J.C., Minkoulou, E., Salah, J. and Balkau, B. (1998) The Prevalence of Hypertension in Rural and Urban Cameroon. International Journal of Epidemiology, 27, 181-185. http://dx.doi.org/10.1093/ije/27.2.181

[31] Nethononda, M.R., Essop, M.R., Mbewu, A.D. and Galpin, J.S. (2004) Coronary Artery Disease and Risk Factors in Black South Africans-A Comparative Study. Ethnicity \& Disease, 14, 515-519.

[32] Ekpe, E.E., Aghaji, M.A., Edaigbini, S.A., Onwuta, C.N. and Anisiuba, B. (2008) Cardiac Pacemaker Treatment of Heart Block in Enugu: A 5-Year Review. Nigerian Journal of Medicine, 17, 7-12. http://dx.doi.org/10.4314/njm.v17i1.37346

[33] Adeoye, P.O., Okonta, K.E., Salami, M.A. and Adegboye, V.O. (2013) Experience with Permanent Pacemaker Insertion at the University College Hospital, Ibadan, Nigeria. Nigerian Journal of Cardiology, 10, 3-5. http://dx.doi.org/10.4103/0189-7969.118572

[34] Omotoso, A. and Kane, A. (2000) Intraventricular Conduction Block in Adult Nigerians with Hypertensive Heart Disease; Epidemiological Study of Cardiovascular Disease and Risk Factors in Senegal: Cardiology—Out of Africa. Cardiovascular Journal of South Africa, 11, 173-174.

[35] Olurin, E.O., Itayemi, S.O., Oluwasanmi, J.O. and Ajayi, O.O. (1973) The Pattern of Thyroid Gland Diseases in Ibadan, Nigeria. Nigerian Medical Journal, 3, 58-65.

[36] Evangelopoulou, M.E., Alevizaki, M., Toumanidis, S., Piperingos, G., Mavrikakis, M., Sotou, D., Evangelopoulou, K. and Koutras, D.A. (1999) Mitral Valve Prolapse in Autoimmune Thyroid Disease: An Index of Systemic Autoimmunity? Thyroid, 9, 973-977. http://dx.doi.org/10.1089/thy.1999.9.973

[37] Ogbera, A.O., Fasanmade, O. and Adediran, O. (2007) Pattern of Thyroid Disorders in the Southwestern Region of Nigeria. Ethnicity \& Disease, 17, 327-330.

[38] Fokou, M., Ashuntantang, G., Teyang, A., Kaze, F., Chichom Mefire, A., Halle, M.P., et al. (2012) Patients Characteristics and Outcome of 518 Arteriovenous Fistulas for Hemodialysis in a Sub-Saharan African Setting. Annals of Vascular Surgery, 26, 674-679. http://dx.doi.org/10.1016/j.avsg.2011.07.019

[39] Alhassan, S.U., Adamu, B., Abdu, A. and Aji, S.A. (2013) Outcome and Complications of Permanent Hemodialysis Vascular Access in Nigerians: A Single Centre Experience. Annals of African Medicine, 12, 127-130. http://dx.doi.org/10.4103/1596-3519.112410

[40] Liam, C.K., Lim, K.H. and Wong, C.M. (2000) Causes of Pleural Exudates in a Region with a High Incidence of Tuberculosis. Respirology, 5, 33-38. http://dx.doi.org/10.1046/j.1440-1843.2000.00223.x

[41] Okonta, K.E., Anbarasu, M. and Kanagaraj, G. (2011) Intra-Aortic Balloon Pump in Coronary Artery Bypass GraftFactors Affecting Outcome. Journal of West African College of Surgeons, 1, 15-25.

[42] Spodick, D.H. (1997) The Pericardium. Marcel Dekker, Inc., New York.

[43] Syed, F.F., Ntsekhe, M., Mayosi, M.B. and Jae, K. (2013) Effusive-Constrictive Pericarditis. Heart Failure Reviews, 18, 277-287. http://dx.doi.org/10.1007/s10741-012-9308-0

[44] Fullerton, D.A. and Harken, H.A. (2007) Acquired Heart Disease: Valvular. In: Townsend, C.M., Beauchamp, R.D., Evers, B.M. and Mattox, K.L., Eds., Sabiston Textbook of Surgery, 18th Edition, Saunders, Philadelphia.

[45] Chen, M.Y., Chen, Y.S., Chen, S.J. and Lu, C.W. (2011) A Girl with Right Heart Failure Related to Effusive-Constrictive Pericarditis. Pediatric Cardiology, 32, 681-684. http://dx.doi.org/10.1007/s00246-011-9927-6

[46] Sagrista-Sauleda, J., Angel, J., Sanchez, A., Permanyer-Miralda, G. and Soler-Soler, J. (2004) Effusive-Constrictive Pericarditis. New England Journal of Medicine, 350, 469-475. http://dx.doi.org/10.1056/NEJMoa035630

[47] Enriquez-Sarano, M., Schaff, H.V. and Frye, R.L. (1997) Early Surgery for Mitral Regurgitation: The Advantages of Youth. Circulation, 96, 4121-4123.

[48] Swan, H.J., Forrester, J.S., Diamond, G., Chatterjee, K. and Parmley, W.W. (1972) Hemodynamic Spectrum of Myocardial Infarction and Cardiogenic Shock: A Conceptual Model. Circulation, 42, 1097-1110. http://dx.doi.org/10.1161/01.CIR.45.5.1097

[49] Cleland, J.G. and McGowan, J. (1999) Heart Failure Due to Ischaemic Heart Disease: Epidemiology, Pathophysiology and Progression. Journal of Cardiovascular Pharmacology, 33, S17-S29.

[50] Borer, J.S., Rosing, D.R., Miller, R.H., Stark, R.M., Kent, K.M., Bacharach, S.L., et al. (1980) Natural History of Left ventricular Function during One Year after Acute Myocardial Infarction: Comparism with Clinical, Electrocardiographic and Biochemical Determinations. American Journal of Cardiology, 46, 1-12.

[51] Jiang, L., Levine, R.A., King, M.E. and Weyman, A.E. (1987) An Integrated Mechanism for Systolic Anterior Motion of the Mitral Valve in Hypertrophic Cardiomyopathy Based on Echocardiographic Observations. American Heart Journal, 113, 633-644. http://dx.doi.org/10.1016/0002-8703(87)90701-0 
[52] Stern, A.B. and Klemmer, P.J. (2011) High-Output Heart Failure Secondary to Arteriovenous Fistula. Hemodialysis International, 15, 104-107. http://dx.doi.org/10.1111/j.1542-4758.2010.00518.x

[53] Wasse, H. and Singapuri, M.S. (2012) High-Output Heart Failure: How to Define It, When to Treat It, and How to Treat It. Seminars in Nephrology, 32, 551-557. http://dx.doi.org/10.1016/j.semnephrol.2012.10.006

[54] Neff, T.A. and Buchanan, B.D. (1975) Tension Pleural Effusion. A Delayed Complication of Pneumothorax Therapy in Tuberculosis. American Review of Respiratory Disease, 111, 543-548.

[55] Samet, P. (1973) Hemodynamic Sequelae of Cardiac Arrhythmias. Circulation, 47, 399-407. http://dx.doi.org/10.1161/01.CIR.47.2.399

[56] Degroot, W.J. and Leonard, J.J. (1970) Hyperthyroidism as a High Cardiac Output State. American Heart Journal, 79, 265-275. http://dx.doi.org/10.1016/0002-8703(70)90318-2

[57] Durhan, D. and Worthley, L.I. (2002) Cardiac Arrhythnias: Diagnosis and Management. The Bradycardias. Critical Care and Resuscitation, 4, 54-60.

[58] Czarkowski, M., Hilgertner, L., Powalowski, T., Radomski, D. and Mikulska, M. (2005) Is the Resistance of Large Conduit Arteries also Decreased in Thyrotoxic Patients with Grave’s Disease? Thyroid, 15, 377-381. http://dx.doi.org/10.1089/thy.2005.15.377

[59] Klein, I. and Danzi, S. (2007) Cardiovascular Involvement in General Medical Conditions. Thyroid Disease and the Heart. Circulation, 116, 1725-1735. http://dx.doi.org/10.1161/circulationaha.106.678326 
Scientific Research Publishing (SCIRP) is one of the largest Open Access journal publishers. It is currently publishing more than 200 open access, online, peer-reviewed journals covering a wide range of academic disciplines. SCIRP serves the worldwide academic communities and contributes to the progress and application of science with its publication.

Other selected journals from SCIRP are listed as below. Submit your manuscript to us via either submit@scirp.org or Online Submission Portal.
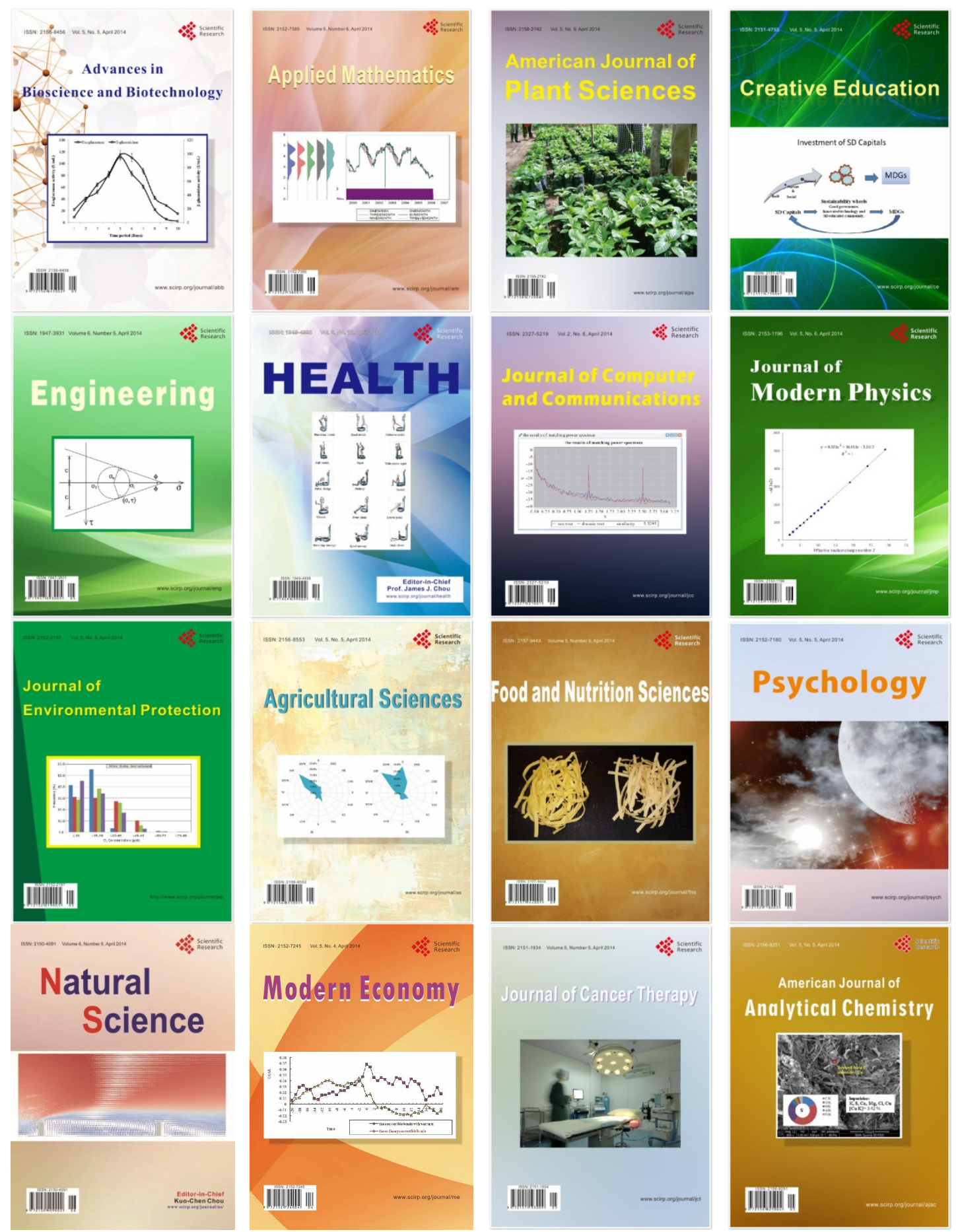